\title{
Mechanical determinants of faster change of direction speed performance in male athletes
}

Original Research

Funding Statement: No external funding was received for this work.

Conflict of Interest: There are no conflicts of interest concerning this paper

Thomas Dos'Santos", Christopher Thomas, Paul, A. Jones \& Paul Comfort

Human Performance Laboratory, Directorate of Sport, Exercise, and Physiotherapy,

University of Salford, Greater Manchester, United Kingdom

${ }^{\#}$ Corresponding Author: Thomas Dos'Santos

Telephone: +447961744517

Email: t.dossantos@hotmail.co.uk

Preferred running head: Mechanical determinants and change of direction speed

Abstract word count: 255 words

Manuscript word count: 4639 words

Number of tables and figures: 5 Tables, 1 Figures 


\section{ABSTRACT}

Mechanical variables during change of directions for example braking and propulsive forces, impulses and ground contact times (GCT) have been identified as determinants of faster change of direction speed (CODS) performance. The purpose of this study was to investigate the mechanical determinants of $180^{\circ}$ CODS performance with mechanical characteristic comparisons between faster and slower performers; whilst exploring the role of the penultimate foot contact (PEN) during the change of direction. Forty multidirectional male athletes performed six modified $505(\bmod 505)$ trials $(3$ left and right) and ground reaction forces were collected across the PEN and final foot contact (FINAL) during the change of direction. Pearson's correlation coefficients and co-efficients of determination were used to explore the relationship between mechanical variables and mod505 completion time. Independent T-Tests and Cohen's $d$ effect sizes (ES) were conducted between faster $(\mathrm{n}=10)$ and slower $(\mathrm{n}=10)$ mod505 performers to explore differences in mechanical variables. Faster CODS performance was associated $(\mathrm{p}<0.05)$ with shorter GCTs $(r=0.701-0.757)$, greater horizontal propulsive forces ( $\mathrm{r}=-0.572$ to -0.611 ), greater horizontal braking forces (HBF) in the PEN ( $r=-0.337)$ lower HBF ratios $(r=-0.429)$ and lower FINAL vertical impact forces (VIF) $(r=0.449-0.559)$. Faster athletes demonstrated significantly $(\mathrm{p}<0.05, E S=1.08-2.54)$ shorter FINAL GCTs, produced lower VIF, lower HBF ratios and greater HPF in comparison to slower athletes. These findings suggest that different mechanical properties are required to produce faster CODS performance, with differences in mechanical properties observed between fast and slower performers. Furthermore, applying a greater proportion of braking force during the PEN relative to the FINAL may be advantageous for turning performance. 
KEY WORDS braking force, propulsive force, ground contact time, penultimate foot contact, turning

\section{INTRODUCTION}

The ability to change direction quickly while running at high speed is essential for many multidirectional field and invasion sports $(2,5,35,45)$. Of importance is change of direction speed (CODS) which is defined as 'the ability to decelerate, reverse or change movement direction and accelerate again' (24). No immediate reaction to a stimulus is required therefore, the direction change is pre-planned; requiring no perceptual or decision making factors $(5,45)$. Change of direction speed tasks are typically closed skills involving preplanned movements such as baseball or softball whereby the batters run between bases and change direction at angles influenced by the diamond (45) and cricket where batters run between the wickets. However, CODS has been suggested as 'the ability to change initial direction to a predetermined location and space on a field or court' therefore applicable to specific situations in open skilled sports (31).

Successful CODS performance is suggested to be influenced by numerous factors including technique (body lean and posture, foot placement, stride adjustment), straight line sprint speed and lower limb strength and power qualities (strength, power, rate of force development and reactive strength) $(35,46)$. It should be acknowledged that the kinetic and kinematic requirements will be largely influenced by the anthropometrics and the type and angle of the $\operatorname{COD}(6,13-16)$. 
Importantly, the strength qualities that an athlete possesses are essential because during a change of direction an athlete must possess sufficient eccentric strength (braking phase), isometric strength (plant phase) and concentric strength (propulsive phase) (39) to allow rapid deceleration and subsequent reacceleration in the new intended direction. Changing direction requires rapid and systematically co-ordinated force and impulse application during the braking, plant and propulsive phases of the movement whilst maintaining optimal body positioning $(38,39)$. Practitioners and scientists are interested in the optimal techniques and resistance training methods for COD performance and minimising risk of injury (16).

Greater relative horizontal and vertical braking and propulsive impulses, propulsive and braking forces and shorter ground contact times (GCT) in the final foot contact (FINAL) have been identified as determinants of faster CODS performance $(12,16,38,39)$. Greater relative braking impulse and force during the deceleration phase are fundamental to reduce the velocity of the centre of mass (COM) (change in momentum) and allow the body to rotate and align in the new intended direction (23); thus heavily dependent on eccentric strength (40). Moreover, the application of greater braking force and impulse during the deceleration phase $(12,38)$ results in increased storage and utilisation of elastic energy as the muscle lengthens under eccentric load $(22,38)$; subsequently, allowing greater propulsive forces and impulse from the transition into propulsive phase (concentric), resulting in shorter GCTs, and greater exit velocities $(12,38,39)$. Although, to our knowledge only one study has investigated the kinetic demands during a high velocity 505 CODS task $\left(180^{\circ}\right)$; it is unknown whether a similar observation would be found for lower velocity mod505 performance. Consequently, coaches and practitioners require information regarding the kinetic demands of lower velocity $180^{\circ}$ turns given the importance in COD multidirectional sports $(2,5,35,45)$. 
To date a large proportion of biomechanical investigations of CODS have inspected the ground reaction force (GRF) of the final foot contact of the change of direction $(16,28,34$, 38, 39, 43); reporting greater propulsive and braking impulses and forces, and shorter GCTs as determinants of faster CODS performance $(16,28,34,38,39)$. However, investigations establishing the role of the penultimate foot contact (PEN) during CODS performance are limited $(11,15,25,26)$; studies show that PEN prior to the FINAL during the change of direction plays a pivotal role during deceleration. Athletes which produce greater braking forces in the PEN relative to the FINAL during change of directions subsequently experience reductions in braking force and knee abduction moments in the pivot or cutting limb; thus reducing knee joint loads and potentially risk of injury $(11,25,26)$. Conversely, the role of the PEN for CODS performance remains inconclusive as the aforementioned studies have not explored the relationship of the PEN mechanical variables with CODS performance. To our knowledge, Graham-Smith et al. (11) is the only investigation to examine GRF in the PEN and CODS performance reporting greater PEN horizontal braking forces were associated with faster CODS ( $\mathrm{r}=-0.674)$, however this study was only presented in abstract format. Therefore, the role of the braking in the PEN with CODS performance warrants further investigation as practioners require information regarding the optimal techniques for faster turning performance.

The mechanical, neuromuscular and physiological demands of changes of direction are angle dependent $(6,13-16)$ and it has been documented that changes of direction with increased angles $(7,15,36)$ and approach velocity (43) require greater braking forces to reduce the velocity of the COM and allow the rapid application of force into the new intended direction. 
Theoretically, if athletes can predominantly produce greater braking force during the PEN when entering a change of direction of high angle and velocity, this should subsequently allow a reduction in knee joint loads in the FINAL and greater focus on propulsive force application into the new intended direction. However, this theory requires investigating to determine the mechanical determinants of CODS performance and mechanical differences between fast and slow performers. This may offer practitioners new coaching guidelines and techniques for faster CODS performance,

The aim of this study was to investigate the mechanical determinants of $180^{\circ}$ CODS performance whilst exploring the role of the PEN during the change of direction. A secondary aim was to compare mechanical characteristics between faster and slower CODS performers. It is hypothesised that faster CODS performance will be associated with shorter GCTs in the PEN and FINAL. Further, it is hypothesized that faster CODS performance will be associated with greater relative braking forces in the PEN and higher propulsive forces in the FINAL, respectively.

\section{METHODOLOGY}

\section{Experimental Approach to the problem}

This study used a cross sectional design where 40 subjects were assessed for GRF mechanical variables during a modified505 $(\bmod 505)$ CODS test over one testing session. This study aimed to via Pearson's correlation coefficients and co-efficients of determination determine 1) the biomechanical characteristics of mod505 performance, specifically relating to PEN and FINAL; 2) differences in mechanics between faster and slower performers in mod505 via independent T-Tests and Cohen's $d$ effects sizes similar to previous research (39). 


\section{$\underline{\text { Subjects }}$}

Male athletes participated in this study $(n=40$; mean \pm sd: age: $23.0 \pm 2.9$ years; mass: 88.05 $\pm 12.86 \mathrm{~kg}$; height: $1.82 \pm 0.07 \mathrm{~m}$ ) consisting of 21 sub-elite rugby league players who performed 4-5 rugby specific sessions, plus three resistance training sessions per week; and 19 collegiate athletes (soccer, rugby, cricket) who performed 3 sport specific sessions, plus two resistance training sessions and one match a week. Data collection took place at the end of pre-season for the sub-elite rugby athletes having completed two four week mesocycles of strength endurance and strength respectively; and in season for collegiate athletes, performing a strength maintenance mesocycle. All athletes participated in a sport that required multiple turns and sprints (invasion, court based and racquet sports) for the last twelve months. All subjects had minimum one year resistance training experience and were free from lower limb injuries six months prior to testing. All subjects were instructed to wear appropriate clothing and footwear, not have consumed alcohol 24 hours or caffeine two hours prior to testing. The investigation was approved by the institutional ethics review board, and all subjects were informed of the benefits and risks of the investigation prior to signing an institutionally approved consent document to participate in the study. The study conformed to the principles of the World Medical Association's Declaration of Helsinki. Subjects were instructed to maintain their normal diet and refrain from training 48 hours prior to the testing session.

\section{$\underline{\text { Procedures }}$}

Testing was conducted over one session (9:30-11:30 am) before sports specific training; consisting of a 15 minute warm up and six $\operatorname{mod505}$ trials (3 trials left and right). Anthropometric assessments [Height $(\mathrm{m})$ and mass $(\mathrm{kg})]$ were completed before performing a standardised warm up. 


\section{Change of Direction Speed Warm Up}

All subjects performed a standardised progressive warm up directed by the investigator similar to the warm ups performed before field and court based sessions for their sports. The warm up included five minutes of non-fatiguing dynamic stretches, activation and mobilisation exercises including body weight squats and lunges before progressing to 10 minutes of foot work, running and turning drills and practice trials of the mod505.

\section{Change of Direction Speed Assessment}

Change of direction speed was assessed by a modified 505 test (Figure 1) on an indoor track (Mondo, SportsFlex, $10 \mathrm{~mm}$; Mondo America Inc., Mondo, Summit, NJ, USA) in the University human performance laboratory following the same procedures as described by Thomas et al. (42). Completion time was measured using Brower timing gates (Draper, UT, USA) placed approximately at hip height for all athletes. All subjects performed six trials in an alternating order; three changing direction with a left FINAL (mod505 left), and three changing direction with a right FINAL (mod505 right) interspersed with two minutes rest between trials. Subjects were allowed three practice attempts to familiarise themselves with the movement patterns required. Athletes were instructed to sprint to a line marked $5 \mathrm{~m}$ from the start, planting their left or right foot on the line, turn $180^{\circ}$ and sprint back $5 \mathrm{~m}$ through the finish. Subjects contacted two AMTI (Model no. 600900; Advanced Mechanical Technology Inc) force plates embedded into the track with their feet to assess PEN and FINAL GRF during the change of direction sampling at $1200 \mathrm{~Hz}$; similar to previous investigations (11, 25). Subjects placed their left or right foot on or past the line depending on the trial. Standardised footwear could not be provided therefore this study did not control for the effects of shoe surface friction. 
AMTI force plates recorded GRF data during the PEN and FINAL and collected via Q-Track Manager software (version1.10.282; Qualisys). Penultimate foot contact was defined as the $2^{\text {nd }}$ last foot contact with the ground prior to moving into a new intended direction and FINAL defined as the phase during a pivot when an individual makes contact with the ground and initiates movement into a different direction. Dependent variables were derived from the force-time curve and analysed using a customised analysis spreadsheet, these included: GCTs, peak horizontal braking force (HBF), peak horizontal propulsive force (HPF), peak vertical impact force (VIF), peak vertical propulsive force (VPF) and horizontal braking force (HBFR) ratio $(25,26,39)$.

Ground contact time for PEN and FINAL was defined as the instant after ground contact in which the vertical GRF was higher than 20 N, and end of contact was defined as the point where the vertical GRF subsided past $20 \mathrm{~N}$ (25). Peak horizontal braking force relative to body mass (BM) was assessed for PEN and FINAL (Peak horizontal GRF produced during weight acceptance phase $\div \mathrm{BM}$ ). The horizontal GRF is the resultant of the medio-lateral and anterior-posteriors GRF's (RESULTANT $\left.=\sqrt{ } \mathrm{ML}^{2}+\mathrm{A}-\mathrm{P}^{2}\right)(25)$. Weight acceptance was defined as the period from initial contact to the first trough in vertical GRF (36). Peak horizontal propulsive force was expressed relative to BM (Peak horizontal GRF produced during propulsive phase $\div \mathrm{BM}$ ) for the FINAL. The horizontal GRF was the resultant of the medio-lateral and anterior-posterior GRF's $\left(\right.$ RESULTANT $\left.=\sqrt{ } \mathrm{ML}^{2}+\mathrm{A}-\mathrm{P}^{2}\right) . \quad$ Peak vertical impact force during weight acceptance was expressed relative to BM (Peak vertical GRF force during weight acceptance phase $\div$ BM) and assessed for PEN and FINAL. Peak vertical propulsive force during the FINAL was expressed relative to BM (Peak vertical GRF force 
produced at drive off phase $\div \mathrm{BM}$ ). To provide an indication of the deceleration strategy from PEN and FINAL, a FINAL HBF $\div$ PEN HBF braking force ratio was calculated $(25,26)$. The mean of three trials for all variables were used for statistical analysis.

**Insert Figure 1 about here**

\section{$\underline{\text { Statistical Analyses }}$}

Statistical analysis was performed using SPSS software version 22 (SPSS, Chicago, Ill, USA) and a custom reliability spreadsheet (19). Normality was confirmed for all variables using a Shapiro Wilks-test. Within-session reliability was assessed via intraclass correlation coefficients (ICC), 95\% confidence intervals (CI), coefficient of variation (CV) and typical error of measurement (TE) expressed as $\mathrm{CV}$ between the three trials for each dependent variable using a custom spreadsheet (19). The CV was calculated based on the mean square error term of logarithmically transformed data (19). To assess the magnitude of the ICC the threshold values were $0.1,0.3,0.5,0.7,0.9$ and 1.0 for low, moderate, high, very high, nearly perfect and perfect, respectively (17). Power was calculated using $\mathrm{G}^{*}$ Power (Version 3.1, University of Dusseldorf, Germany) (9). Mean and standard deviations were calculated for all dependent variables.

Relationships between completion time and mechanical variables were analysed using Pearson's product-moment correlation via SPSS and co-efficients of determination. Correlations were evaluated as follows: small $(0.10-0.29)$, moderate $(0.30-0.49)$, large $(0.50-0.69)$, very large $(0.70-0.89)$, nearly perfect $(0.90-0.99)$, and perfect $(1.0)(18)$. Further, comparisons were made between the fastest and slowest mod505 performers (upper and lower $25 \%$ of the sample) for mechanical variables. Independent sample T-Tests and 
Cohen's $d$ effect sizes (ES) were implemented to assess the magnitude of differences in mechanical characteristics between fast and slow performers. Similarly, paired sample TTests and ESs were also performed between PEN and FINAL mechanical variables to assess the magnitude of differences in VIF and HBF. Effect sizes were calculated by the formula Cohen's $d=\mathrm{M}-\mathrm{M} 2 / \sigma$ pooled (10). Effect sizes were interpreted as trivial (<0.19), small $(0.20-0.59)$, moderate $(0.60-1.19)$, large $(1.20-1.99)$, and very large $(2.0-4.0)(20)$. The criterion for significance was set at $p \leq 0.05$.

\title{
RESULTS
}

Descriptive statistics for mod505 completion time and mechanical variables are presented in Table 1. Intraclass correlation coefficients, CV (95\% CIs) and TE are presented in Table 1 for all dependent variables revealing very high to nearly perfect ICC within-session reliability measures for left and right $\bmod 505$ ( $\mathrm{ICC}=0.85-0.90, \mathrm{CV}=2-2.5 \%$ ) completion time respectively. Mechanical variables in the PEN and FINAL demonstrated very high withinsession reliability measures (ICC $\geq 0.7, C V=7.2-18.2 \%$ ), excluding VPF (mod505 left) and HBFR $(\bmod 505$ left $)$ which demonstrated lower reliability measures $(\mathrm{ICC}=0.52-0.62, \mathrm{CV}=$ $9.0-19.6 \%)$.

\author{
**Insert Table 1 about here**
}

Pearson's correlations and co-efficients of determination between mechanical variables and CODS performance are presented in Table 2. Specifically, FINAL GCT demonstrated very large significant correlations with CODS performance $(r=0.701-0.757, \mathrm{p}<0.01)$ explaining the largest variance for both mod505 left $(49.1 \%)$ and right $(57.3 \%)$ performance. Large significant inverse correlations were observed between HPF and CODS performance ( $\mathrm{r}=$ 0.572 to $\left.-0.611, \mathrm{r}^{2}=0.327-0.373, \mathrm{p}<0.01\right)$. Moderate to large correlations were observed 
between FINAL VIF and CODS performance $\left(r=0.449-0.559, r^{2}=0.202-0.312, p<0.01\right)$, while FINAL HBF also demonstrated a moderate relationship with mod505 right performance $\left(r=0.331, r^{2}=0.110, p<0.05\right)$. During the PEN moderate significant correlations were observed between HBF and mod505 left performance $\left(r=-0.337, r^{2}=0.114, p<0.05\right)$ and VIF and mod505 right $\left(r=0.337, \mathrm{r}^{2}=0.112, \mathrm{p}<0.05\right)$. Furthermore, a moderate significant correlation $\left(r=0.429, r^{2}=0.184, p<0.05\right)$ was revealed between HBFR and mod505 left performance.

**Insert Table 2 about here**

Independent T-Tests revealed significant differences between fast and slowest groups for $\bmod 505$ left $(\mathrm{p}<0.001, \mathrm{ES}=8.48)$ and right $(\mathrm{p}<0.001, \mathrm{ES}=6.46)$ CODS performance, respectively. Examination and comparisons of the mechanical variables during the PEN and FINAL between fast and slower performers are presented in Tables 3 and 4 with descriptive data, p values and ESs reported. Faster mod505 left performers (Table 3) demonstrated significantly greater $\operatorname{HBF}(p=0.027)$ in the PEN, larger HPF $(p=0.002)$, lower HBFR $(\mathrm{p}=0.006)$, shorter GCTs $(\mathrm{p}<0.001)$ and lower VIF $(\mathrm{p}=0.007)$ in the FINAL in comparison to slower performers. Faster mod505 right athletes demonstrated in the FINAL (Table 4) significantly shorter GCTs $(p<0.001)$, lower VIF $(p=0.017)$ and greater HPF $(p<0.001)$ in contrast to slower performers.

\footnotetext{
**Insert Table 3 about here**

**Insert Table 4 about here $* *$
}

Comparisons of braking force variables between the PEN and FINAL are presented in Table 6. Significantly $(\mathrm{p}<0.05)$ larger PEN VIF was found in comparison to the FINAL for mod505 
left performance, whereas larger FINAL HBF was applied in contrast to the PEN during the mod505 right.

**Insert Table 5 about here**

\section{DISCUSSION}

The aim of this study was to investigate the mechanical determinants of faster $180^{\circ} \mathrm{CODS}$ performance whilst establishing the role of the PEN during the change of direction. This study is the first to investigate the mechanical determinants of faster CODS performance in a large male sample while examining the role of the PEN during CODS performance. The main findings from the study are that key mechanical differences exist between faster and slower CODS performers with faster athletes demonstrating significantly shorter FINAL GCTs, greater HPFs, and lower VIFs. Further, the results also suggest that PEN braking forces play an important role during deceleration prior to the change of direction and propulsion phase, respectively.

The present study found that the main determinant of CODS performance was shorter GCTs in the FINAL explaining $49.1-57.3 \%$ of variance. This is in agreement with the hypotheses of the present study; with corroborative studies demonstrating similar findings $(28,34)$. Shorter GCTs during a change of direction are advantageous as athletes will spend less time braking and propelling themselves into the new direction, subsequently resulting in faster CODS performance. As a COD involves an eccentric-concentric coupling action in the FINAL (33) and our results illustrate the importance of rapid force application in short GCTs, practioners and coaches may consider lower limb plyometric training for the enhancement of 
CODS performance $(1,29)$. As CODs are a multiplanar movement, multidirectional lower limb plyometric exercises can be implemented to positively improve CODS performance (1, 29) given the similarity of the push off mechanism during a COD (46).

A further determinant was HPF inversely explaining 32.7-37.3\% of CODS performance (Table 2). This suggests that athletes who apply greater relative amounts horizontal force in the FINAL results in quicker CODS performance. Hypothetically, the faster athletes are applying horizontal force technically and more efficiently to propel into the new intended direction and should exit the COD with a greater velocity. Similar observations in female athletes have been observed with faster 505 performance in athletes who apply greater propulsive forces in shorter GCTs (39).Therefore, athletes who apply greater HPFs, in shorter GCTs demonstrate faster CODS performance which is likely due to increased braking force and therefore deceleration during the PEN (Tables 2-4).

This study is the first to investigate the role of the PEN for CODS performance in a large male sample. Interestingly, PEN HBF demonstrated a moderate inverse relationship with mod505 left $(r=-0.326)$ and a moderate correlation was observed with HBFR $(r=0.429)$ and mod505 left. Corroborative research has also demonstrated associations between greater PEN HBF ( $\mathrm{r}=-0.674)$ and faster CODS (11). Mechanical characteristic differences were found between faster and slower performers, revealing mod505 left faster athletes produced significantly $(\mathrm{p}<0.05)$ greater PEN HBF, lower HBFR and although not significantly different, shorter PEN GCTs ( $\mathrm{p}=0.077, \mathrm{ES}=0.88$ ) (Tables 3 \& 4). This suggests that greater PEN HBF in shorter GCTs are associated with faster CODS performance, and greater PEN braking relative to the FINAL is associated with faster performance. The application of 
braking force is essential for successful CODS performance $(23,35,39)$; the results of the present study suggest it is advantageous to apply greater HBF in the PEN and greater forces here relative to the FINAL because braking earlier should reduce the horizontal momentum of the COM to allow more effective weight acceptance and preparation for drive-off propulsive forces (body rotation and alignment into the new intended direction) (23).

The findings from this study suggest it is advantageous to apply a greater proportion of HBF in the PEN relative to the FINAL, as it is a more efficient deceleration strategy for faster CODS performance. Consequently, practitioners should consider coaching their athletes a deceleration strategy which consists of a higher proportion of braking forces in the PEN relative to the final, specifically HBF is key for pre-planned $180^{\circ}$ turn performance. In terms of injury risk, studies have shown a deceleration strategy with smaller HBFRs is advantageous as it reduces knee abduction moments in the turning limb (25) and cutting limb (26) in female soccer players. However, the aforementioned studies did not investigate the biomechanical determinants of faster CODS performance; therefore future investigations into the biomechanical determinants of injury risk and performance during CODS are warranted.

It should be noted the present study implemented a mod505 test whereby the approach distances are shorter than a 505; therefore a lower approach velocity is likely to be achieved due a shorter distance to accelerate. Increased approach velocities into a change of direction result in larger posterior deceleration forces (43), therefore it is anticipated that the 505 with a $15 \mathrm{~m}$ approach would require greater braking forces in the FINAL and PEN. Therefore, the results of the present study are applicable to $180^{\circ}$ change of direction tasks of short approach distances, however further research is required investigating the kinetic demands of $180^{\circ}$ turns of different approach distances and velocities. 
Interestingly, significant mechanical differences between faster and slower performers were observed (Tables $3 \& 4$ ). Moderate to large significant correlations were found between FINAL VIF and CODS performance ( $\mathrm{r}=0.449-0.559)$ while slower performers also produced significantly larger FINAL VIF in contrast to fast performers $(\mathrm{p}<0.05)$. Although not statistically different, small to moderate differences in VIF in the PEN were also observed, whereas faster performers applied lower VIF and greater HBF. Subsequently, this suggests that differences in CODS performance may be explained by kinematic and technical differences during the braking and propulsive phases of the COD. Researchers have highlighted differences in technique and kinematics between faster and slower CODS athletes $(16,28,34,38)$; unfortunately, the present study did not conduct three dimensional analysis or investigate any technical or kinematic analysis of CODS performance. Consequently, further research is required comparing kinematic and technical determinants of faster CODS performance.

Specifically, slower performers applied greater FINAL VIF which is suboptimal as there is a misdirection in force application, whereby larger HBFs and more horizontal force vectors are required to reduce the momentum of the COM (23). The larger VIF in combination with higher HBFR (Tables 3 \& 4) could explain the longer GCTs experienced in the FINAL in slower performers, By applying braking force vertically and not predominantly braking in the PEN could result in a longer time spent braking by the slower athletes and subsequent longer GCTs and slower CODS performance; this has also been revealed in slower female athletes who experiences longer GCTs and longer time spent braking (39). Therefore, it is postulated that the mechanical differences between fast and slower performers in this study were partially attributed to differences in change of direction technique as supported by previous investigations $(16,28,34,38)$ or alternatively could be attributed to differences in strength 
capacity as shown by previous studies $(38,39)$; or a combination of the two. Future investigations should conduct comprehensive comparisons of the strength and movement mechanics (kinetics and kinematics) between fast and slower athletes to improve our understanding of CODS performance.

Surprisingly, only significantly greater $(\mathrm{p}=0.026)$ VIF was observed in the PEN in comparison to the FINAL during mod505 left, whereas greater $\mathrm{HBF}(\mathrm{p}=0.025)$ in the FINAL was found for mod505 right performance. This is in contrast to previous investigations who have observed larger braking forces in the PEN relative to the FINAL $(11,15,25,26)$. However, this difference is likely to be attributed to the longer approach distances in the CODS tasks of abovementioned studies, which would require larger deceleration forces to reduce the momentum prior to changing direction (43).

Spiteri et al. (39) demonstrated that faster 505 and $\mathrm{T}$ test performers displayed significantly greater FINAL vertical braking force in comparison to slower during the $505(\mathrm{p}=0.02$, ES $=$ 1.88). Conversely, this study found faster athletes produced significantly lower FINAL VIF for mod505 tasks $(\mathrm{p}<0.05)$. However, the mod505 test has a lower approach distance and approach velocity so it is expected that braking demands would be lower in contrast to Spiteri et al. (39). Furthermore, kinetic and kinematic differences have been reported between genders for CODS tasks $(30,36,37)$ which may further explain the differences in observations as Spiteri et al. (39) investigated a female sample and the present study investigated male.

Although this study performed correlational analysis and fast vs slow comparison on the GRF variables during a COD, the main findings where high amounts of horizontal propulsive force in short GCTs, were indicative of faster CODS performance. Further, also greater HBF in the 
penultimate step were also linked to faster performance. Given the importance of the rapid application of propulsive and braking forces for faster CODS performance, and strength has been identified as a pivotal component of CODS performance $(35,40,41,44)$; practitioners are encouraged to develop their athletes bilateral strength and rate of force development qualities including eccentric, isometric and concentric strength $(35,46)$. Unilateral strength should also be targeted for increased specificity due to the unilateral requirements of CODs. Researchers have revealed a positive transfer of dynamic strength training to CODS performance $(27,32)$ while more recently researchers have observed improvements in CODS performance due to improvements in COD kinetic parameters including GCT, braking and propulsive forces following 10 weeks of eccentric strength training (8). Consequently, a welldeveloped strength capacity should be developed in a periodised training programme for the enhancement of CODS.

The male population used in this study demonstrated very high to nearly perfect ICC withinsession reliability measures with low $\mathrm{CV}$ for CODS performance (ICC $\geq 0.85, \mathrm{CV} \leq 2.5 \%$ ), comparable to previous studies $(2,42)$. Interestingly, the mechanical variables demonstrated lower within-session reliability measures (Table 1) comparable to previous research (28), which is most likely to be attributed to movement variability rather than noise (3). This suggests there is variability in the changes of directions between trials, although highly reliable completion times are still achieved. Previous studies who have conducted kinetic analysis of CODS tasks have failed to report their reliability measures $(15,16,38,39)$, which makes it difficult to compare findings. Nonetheless, movement variability is common, having been reported in sporting movements including basketball shooting, javelin throwing and running (3). 
It should be noted that the CODS task was pre-planned rather than an unanticipated movement, where it should be noted that kinetics and kinematics can vary $(4,21)$; therefore is an area for further research. Additionally, it was not feasible to supply and standardise footwear for all subjects therefore this study did not control for the effects of shoe surface friction. A further limitation was a $180^{\circ}$ turn was only investigated with kinetic analysis only, however the mechanical, neuromuscular and physiological demands of change of directions are angle dependent $(6,7,13-16,36)$ thus our findings are applicable to $180^{\circ}$ change of directions. Consequently, there is a requirement for further research investigating the kinetic and kinematic determinants on changes of direction of different angles, and unanticipated changes of directions; while also establishing the role of the PEN for deceleration.

\section{PRACTICAL APPLICATIONS}

In light of the mechanical variables that were associated with faster turning performance, practitioners and scientists are encouraged to develop their athlete's lower limb strength capacity (eccentric, isometric, concentric) and rate of force development. This is due to the importance of the rapid application of high amounts of propulsive and braking forces in short GCTs for faster CODS performance. Further, it is proposed that a pre-planned $180^{\circ}$ turning technique which consists of a greater proportion of HBF in the PEN relative to FINAL is advantageous for faster turning performance. In addition, a technique with high HPF in short GCTs during the FINAL is also advantageous. 


\section{ACKNOWLEDGEMENTS}

The authors would like to thank Phil Graham-Smith for the permission and use of his analysis spreadsheet. No grant funding was received to support this research and the authors have no conflict of interest.

\section{REFERENCES}

1. Asadi A, Arazi H, Young WB, and Saez dVE. The Effects of Plyometric Training on Change of Direction Ability: A Meta Analysis. International journal of sports physiology and performance: Publish ahead of print, 2016.

2. Barber OR, Thomas C, Jones PA, McMahon JJ, and Comfort P. Reliability of the 505 Change of Direction Test in Netball Players. International journal of sports physiology and performance Publish Ahead of Print, 2015.

3. Bartlett $R$, Wheat $J$, and Robins $M$. Is movement variability important for sports biomechanists? Sports Biomechanics 6: 224-243, 2007.

4. Besier TF, Lloyd DG, Ackland TR, and Cochrane JL. Anticipatory effects on knee joint loading during running and cutting maneuvers. Medicine and science in sports and exercise 33: 11761181, 2001.

5. Brughelli M, Cronin J, Levin G, and Chaouachi A. Understanding change of direction ability in sport. Sports Medicine 38: 1045-1063, 2008.

6. Buchheit M, Haydar B, and Ahmaidi S. Repeated sprints with directional changes: do angles matter? Journal of sports sciences 30: 555-562, 2012.

7. Cortes N, Onate J, and Van Lunen B. Pivot task increases knee frontal plane loading compared with sidestep and drop-jump. Journal of sports sciences 29: 83-92, 2011.

8. de Hoyo Ms, SaÃ Ojo JJ, and Gonzalo-Skok O. Effects of 10-week eccentric overload training on kinetic parameters during change of direction in football players. Journal of sports sciences 34 : 1380-1387, 2016.

9. Faul F, Erdfelder E, Buchner A, and Lang A-G. Statistical power analyses using G* Power 3.1: Tests for correlation and regression analyses. Behav Res Methods 41: 1149-1160, 2009.

10. Flanagan EP. The effect size statistic - Applications for the strength and conditioning coach. Strength \& Conditioning Journal 35: 37-40, 2013.

11. Graham-Smith P, Atkinson L, Barlow R, and Jones PA. Braking characteristics and load distribution in 180 o turns. The 5th Annual UK Strength and Conditioning Association Conference\#05/06/2009\#07/06/2009\#Wyboston Lakes, Bedfordshire\#UK, 2009.

12. Green BS, Blake C, and Caulfield BM. A comparison of cutting technique performance in rugby union players. The Journal of Strength \& Conditioning Research 25: 2668-2680, 2011.

13. Hader K, Mendez-Villanueva A, Ahmaidi S, Williams BK, and Buchheit M. Changes of direction during high-intensity intermittent runs: neuromuscular and metabolic responses. $B M C$ sports science, medicine and rehabilitation 6: 2, 2014. 
14. Hader K, Palazzi D, and Buchheit M. Change of Direction Speed in Soccer: How Much Braking is Enough? Kineziologija 47: 67-74, 2015.

15. Havens $\mathrm{KL}$ and Sigward SM. Whole body mechanics differ among running and cutting maneuvers in skilled athletes. Gait \& posture 42: 240-245, 2014.

16. Havens KL and Sigward SM. Cutting mechanics: relation to performance and anterior cruciate ligament injury risk. Medicine and science in sports and exercise 47: 818-824, 2015.

17. Hopkins W, Marshall S, Batterham A, and Hanin J. Progressive statistics for studies in sports medicine and exercise science. Medicine+ Science in Sports+ Exercise 41: 3, 2009.

18. Hopkins WG. Measures of reliability in sports medicine and science. Sports Medicine 30: 1$15,2000$.

19. Hopkins WG. Reliability from consecutive pairs of trials (Excel spreadsheet). A new view of statistics, 2000.

20. Hopkins WG. A scale of magnitudes for effect statistics. A new view of statistics, 2002.

21. Houck JR, Duncan A, and Kenneth E. Comparison of frontal plane trunk kinematics and hip and knee moments during anticipated and unanticipated walking and side step cutting tasks. Gait \& posture 24: 314-322, 2006.

22. Hunter JP, Marshall RN, and McNair PJ. Relationships between ground reaction force impulse and kinematics of sprint-running acceleration. J Appl Biomech 21: 31-43, 2005.

23. Jindrich DL, Besier TF, and Lloyd DG. A hypothesis for the function of braking forces during running turns. Journal of biomechanics 39: 1611-1620, 2006.

24. Jones $P$, Bampouras TM, and Marrin K. An investigation into the physical determinants of change of direction speed. J Sports Med Phys Fitness 49: 97-104, 2009.

25. Jones PA, Herrington LC, and Graham-Smith P. Technique determinants of knee abduction moments during pivoting in female soccer players. Clinical Biomechanics, 2015.

26. Jones PA, Herrington LC, and Graham-Smith P. Technique determinants of knee joint loads during cutting in female soccer players. Human movement science 42: 203-211, 2015.

27. Keiner M, Sander A, Wirth K, Caruso O, Immesberger P, and Zawieja M. Strength performance in youth: trainability of adolescents and children in the back and front squats. The Journal of Strength \& Conditioning Research 27: 357-362, 2013.

28. Marshall BM, Franklyn-Miller AD, King EA, Moran KA, Strike SnC, and Falvey ÃaC. Biomechanical factors associated with time to complete a change of direction cutting maneuver. The Journal of Strength \& Conditioning Research 28: 2845-2851, 2014.

29. McCormick BT, Hannon JC, Newton M, Shultz B, Detling N, and Young WB. The Effects of Frontal-and Sagittal-Plane Plyometrics on Change-of-Direction Speed and Power in Adolescent Female Basketball Players. IJSPP 11, 2016.

30. McLean SG, Walker KB, and van den Bogert AJ. Effect of gender on lower extremity kinematics during rapid direction changes: an integrated analysis of three sports movements. Journal of Science and Medicine in Sport 8: 411-422, 2005.

31. Nimphius S. Increasing Agility. High-Performance Training for SportsChampaign, IL Human Kinetics, 2014.

32. Nimphius S, McGuigan MR, and Newton RU. Relationship between strength, power, speed, and change of direction performance of female softball players. The Journal of Strength \& Conditioning Research 24: 885-895, 2010.

33. Plisk SS. Speed, agility, and speed-endurance development. Essentials of strength training and conditioning: 471-491, 2000.

34. Sasaki S, Nagano Y, Kaneko S, Sakurai T, and Fukubayashi T. The relationship between performance and trunk movement during change of direction. Journal of sports science \& medicine 10: 112, 2011.

35. Sheppard JM and Young WB. Agility literature review: classifications, training and testing. Journal of sports sciences 24: 919-932, 2006. 
36. Sigward SM, Cesar GM, and Havens KL. Predictors of frontal plane knee moments during side-step cutting to 45 and 110 degrees in men and women: implications for anterior cruciate ligament injury. Clinical Journal of Sport Medicine 25: 529-534, 2015.

37. Sigward SM and Powers CM. The influence of gender on knee kinematics, kinetics and muscle activation patterns during side-step cutting. Clinical Biomechanics 21: 41-48, 2006.

38. Spiteri T, Cochrane JL, Hart NH, Haff GG, and Nimphius S. Effect of strength on plant foot kinetics and kinematics during a change of direction task. European journal of sport science 13: 646-652, 2013.

39. Spiteri T, Newton RU, Binetti M, Hart NH, Sheppard JM, and Nimphius S. Mechanical determinants of faster change of direction and agility performance in female basketball athletes. The Journal of Strength \& Conditioning Research 28: 2205-2214, 2015.

40. Spiteri T, Nimphius S, Hart NH, Specos C, Sheppard JM, and Newton RU. The contribution of strength characteristics to change of direction and agility performance in female basketball athletes J Strength Cond Res 28: 2415-2423, 2014.

41. Suchomel TJ, Nimphius S, and Stone MH. The Importance of Muscular Strength in Athletic Performance. Sports Medicine: 1-31, 2016.

42. Thomas $C$, Comfort $P$, Chiang $C-Y$, and Jones PA. Relationship between isometric mid-thigh pull variables and sprint and change of direction performance in collegiate athletes. Journal of Trainology 4: 6-10, 2015.

43. Vanrenterghem J, Venables E, Pataky $T$, and Robinson MA. The effect of running speed on knee mechanical loading in females during side cutting. Journal of biomechanics 45: 24442449, 2012.

44. Watts D. A BRIEF REVIEW ON THE ROLE OF MAXIMAL STRENGTH IN CHANGE OF DIRECTION SPEED. J Aust Strength Cond 23: 100-108, 2015.

45. Young WB, Dawson B, and Henry GJ. Agility and Change-of-Direction Speed are Independent Skills: Implications for Training for. International Journal of Sports Science \& Coaching, 2015.

46. Young WB, James R, and Montgomery I. Is muscle power related to running speed with changed of direction? Journal of Sports Medicine and Physical Fitness 42: 282, 2002. 
Table 1. Completion time, penultimate and final foot contact mechanical variables, and braking force ratio raw values and reliability measures

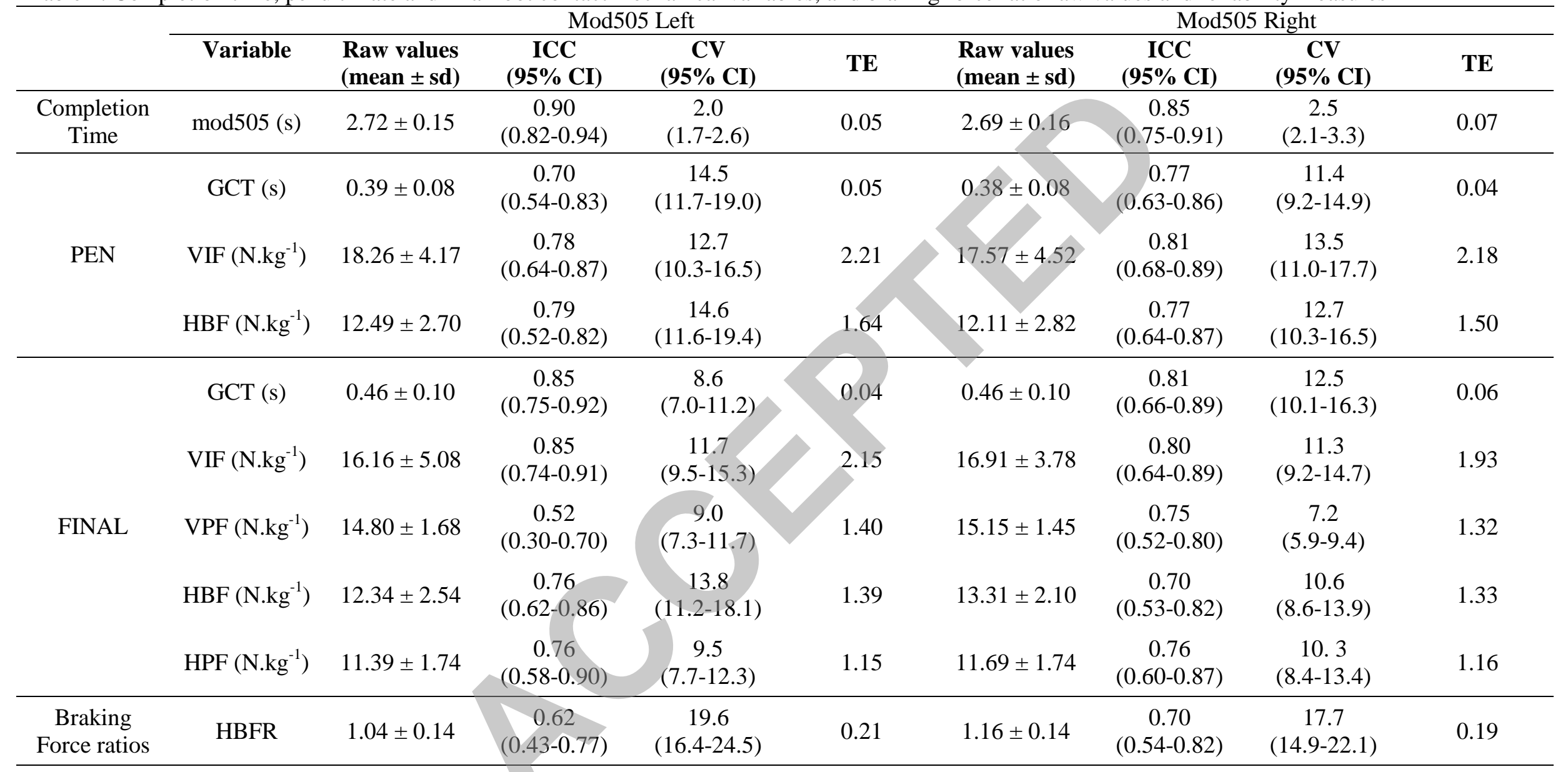

Key: GCT = Ground Contact Time; VIF = Vertical Impact Force; HBF = Horizontal Braking Force; VPF = Vertical Propulsive Force; HPF = Horizontal Propulsive Force; HBFR = Horizontal Braking Force Ratio; ICC = Intraclass Correlation Coefficient; CV= Coefficient of Variation; $\mathrm{CI}=$ Confidence Interval; TE= Typical Error of the measurement; PEN = Penultimate foot contact; FINAL: Final foot contact 
Table 2. Relationship between penultimate and final foot contact mechanical variables, and braking force ratios with CODS performance

\begin{tabular}{|c|c|c|c|c|c|c|c|c|c|}
\hline & & & & Mod505 lef & & & Mod505 rig & & \\
\hline & & $\mathrm{r}$ value & $\mathrm{r}^{2}(\%)$ & $\begin{array}{l}\text { Correlation } \\
\text { magnitude } \\
\text { descriptor }\end{array}$ & $\begin{array}{l}\text { Statistical } \\
\text { Power }\end{array}$ & $\mathrm{r}$ value & $r^{2}(\%)$ & $\begin{array}{c}\text { Correlation } \\
\text { magnitude } \\
\text { descriptor }\end{array}$ & $\begin{array}{l}\text { Statistical } \\
\text { power }\end{array}$ \\
\hline \multirow{3}{*}{ PEN } & $\operatorname{GCT}(\mathrm{s})$ & 0.301 & $0.091(9.1 \%)$ & Moderate & 0.62 & $0^{1}$ & $0.007(0.7 \%)$ & Small & 0.083 \\
\hline & VIF $\left(N \cdot k^{-1}\right)$ & 0.124 & $0.015(1.5 \%)$ & Small & 0.18 & & $0.114(11.4 \%)$ & Moderate & 0.720 \\
\hline & $\operatorname{HBF}\left(\mathrm{N} \cdot \mathrm{kg}^{-1}\right)$ & $-0.337 *$ & $0.112(11.2 \%)$ & Moderate & 0.71 & 0 . & $0.002(0.2 \%)$ & Small & 0.085 \\
\hline \multirow{5}{*}{ FINAL } & GCT (s) & $0.701 * *$ & $0.491(49.1 \%)$ & Very large & 0.99 & $0.757 * *$ & $0.573(57.3 \%)$ & Very large & 1.00 \\
\hline & VIF $\left(\mathrm{N} . \mathrm{kg}^{-1}\right)$ & $0.449 * *$ & $0.202(20.2 \%)$ & Moder & 0.930 & $0.559 * *$ & $0.312(31.2 \%)$ & Large & 0.994 \\
\hline & $\operatorname{VPF}\left(\mathrm{N} . \mathrm{kg}^{-1}\right)$ & 0.046 & $0.002(0.2 \%)$ & Triv & 0.08 & 0.119 & $0.014(1.4 \%)$ & Small & 0.182 \\
\hline & $\operatorname{HBF}\left(\mathrm{N} \cdot \mathrm{kg}^{-1}\right)$ & 0.219 & $0.048(4.8 \%)$ & & & $0.331^{*}$ & $0.110(11.0 \%)$ & Moderate & 0.704 \\
\hline & $\operatorname{HPF}\left(\mathrm{N} . \mathrm{kg}^{-1}\right)$ & $-0.572 * *$ & $0.327(32.7 \%)$ & Large & 0.996 & $-0.611 * *$ & $0.373(37.3 \%)$ & Large & 0.999 \\
\hline $\begin{array}{l}\text { Braking } \\
\text { force ratio }\end{array}$ & HBFR & $0.429 * *$ & $0.184(18.4 \%)$ & Moderate & 0.903 & 0.126 & $0.02(1.6 \%)$ & Small & 0.224 \\
\hline
\end{tabular}

Key: GCT = Ground Contact Time; VIF = Vertical Impact Force; HBF = Horizontal Braking Force; VPF = Vertical Propulsive Force; HPF = Horizontal

Propulsive Force; HBFR = Horizontal Braking Force Ratio; PEN = Penultimate foot contact; FINAL: Final foot contact; * p<0.05; ** p<0.01 
Table 3. Penultimate and final foot contact mechanical variables and braking force ratios comparison between fast and slow mod505 left athletes

\begin{tabular}{|c|c|c|c|c|c|c|c|}
\hline & Variable & $\begin{array}{l}\text { Fast } \\
(\mathrm{n}=10)\end{array}$ & $\begin{array}{l}\text { Slow } \\
(n=10)\end{array}$ & $\begin{array}{c}\mathrm{p} \\
\text { value }\end{array}$ & $\begin{array}{c}\text { Fast vs } \\
\text { slow ES }\end{array}$ & $\begin{array}{c}\text { ES } \\
\text { magnitude } \\
\text { descriptor }\end{array}$ & $\begin{array}{c}\text { Statistical } \\
\text { power }\end{array}$ \\
\hline \multirow{3}{*}{$\begin{array}{c}\text { PEN } \\
\text { comparisons }\end{array}$} & GCT (s) & $0.39 \pm 0.05$ & $0.44 \pm 0.07$ & 0.077 & -0.88 & Moderate & 0.549 \\
\hline & VIF $\left(\right.$ N.kg $\left.{ }^{-1}\right)$ & $18.1 \pm 4.0$ & $19.24 \pm 4.29$ & 0.547 & -0.27 & Small & 0.146 \\
\hline & $\operatorname{HBF}\left(\mathrm{N} \cdot \mathrm{kg}^{-1}\right)$ & $14.2 \pm 2.9$ & $11.3 \pm 2.5$ & 0.027 & 1.08 & & 0.744 \\
\hline \multirow{5}{*}{$\begin{array}{c}\text { FINAL } \\
\text { comparisons }\end{array}$} & GCT (s) & $0.39 \pm 0.03$ & $0.56 \pm 0.11$ & 0.000 & & & 0.998 \\
\hline & VIF $\left(\mathrm{N} \cdot \mathrm{kg}^{-1}\right)$ & $13.2 \pm 2.4$ & $18.7 \pm 5.2$ & & & & 0.898 \\
\hline & $\operatorname{VPF}\left(\mathrm{N} \cdot \mathrm{kg}^{-1}\right)$ & $14.3 \pm 1.3$ & $14.5 \pm 1.3$ & & -0.12 & Trivial & 0.094 \\
\hline & $\operatorname{HBF}\left(\mathrm{N} \cdot \mathrm{kg}^{-1}\right)$ & $11.3 \pm 1.9$ & & & -0.65 & Moderate & 0.375 \\
\hline & HPF $\left(\mathrm{N} \cdot \mathrm{kg}^{-1}\right)$ & $12.4 \pm$ & & 0.002 & 1.61 & Large & 0.963 \\
\hline $\begin{array}{c}\text { Braking } \\
\text { force ratio } \\
\text { comparisons }\end{array}$ & HBFR & $0.82 \pm 0.19$ & 0.30 & 0.006 & -1.5 & Large & 0.936 \\
\hline
\end{tabular}

Key: GCT = Ground Contact Time; VIF = Vertical Impact Force; HBF = Horizontal Braking Force; VPF = Vertical Propulsive Force; HPF = Horizontal Propulsive Force; HBFR = Horizontal Braking Force Ratio; ES = Effect Size; PEN = Penultimate foot contact; FINAL: Final foot contact 
Table 4. Penultimate and final foot contact and braking force ratio comparisons between fast and slow mod505 right athletes

\begin{tabular}{|c|c|c|c|c|c|c|c|}
\hline & Variable & $\begin{array}{c}\text { Fast } \\
(n=10)\end{array}$ & $\begin{array}{l}\text { Slow } \\
(n=10)\end{array}$ & $\mathrm{p}$ value & $\begin{array}{l}\text { Fast vs } \\
\text { slow ES }\end{array}$ & $\begin{array}{c}\text { ES } \\
\text { magnitude } \\
\text { descriptor }\end{array}$ & $\begin{array}{c}\text { Statistical } \\
\text { power }\end{array}$ \\
\hline \multirow{3}{*}{$\begin{array}{c}\text { PEN } \\
\text { comparisons }\end{array}$} & GCT (s) & $\begin{array}{c}0.35 \pm \\
0.07\end{array}$ & $\begin{array}{c}0.39 \pm \\
0.06\end{array}$ & 0.151 & -0.68 & Moderate & 0.372 \\
\hline & $\operatorname{VIF}\left(\mathrm{N} . \mathrm{kg}^{-1}\right)$ & $16.5 \pm 4.2$ & $20.3 \pm 5.4$ & 0.097 & -0.79 & & 0.51 \\
\hline & $\operatorname{HBF}\left(\mathrm{N} \cdot \mathrm{kg}^{-1}\right)$ & $12.4 \pm 3.3$ & $12.4 \pm 3.1$ & 0.986 & 0.01 & & \\
\hline \multirow{5}{*}{$\begin{array}{c}\text { FINAL } \\
\text { comparisons }\end{array}$} & GCT (s) & $\begin{array}{c}0.38 \pm \\
0.08\end{array}$ & $\begin{array}{c}0.57 \pm \\
0.07\end{array}$ & 0.000 & & & 0.999 \\
\hline & VIF (N.kg $\left.{ }^{-1}\right)$ & $15.2 \pm 2.9$ & $19.5 \pm 4.3$ & & -1.19 & Moderate & 0.809 \\
\hline & VPF $\left(\mathrm{N} \cdot \mathrm{kg}^{-1}\right)$ & $15.3 \pm 1.2$ & & & -0.03 & Trivial & 0.070 \\
\hline & $\mathrm{HBF}\left(\mathrm{N} \cdot \mathrm{kg}^{-1}\right)$ & $12.9 \pm$ & & 0.19 & -0.61 & Moderate & 0.366 \\
\hline & $\mathrm{HPF}\left(\mathrm{N} \cdot \mathrm{kg}^{-1}\right)$ & $13.2 \pm 1.7$ & $10.1 \pm 1.0$ & 0.000 & 2.24 & Very large & 0.999 \\
\hline $\begin{array}{c}\text { Braking force } \\
\text { ratio } \\
\text { comparisons }\end{array}$ & HBFR & $\begin{array}{c}1.11 \pm \\
0.35\end{array}$ & $\begin{array}{c}1.20 \pm \\
0.25\end{array}$ & 0.724 & -0.31 & Small & 0.156 \\
\hline
\end{tabular}

Key: GCT = Ground Contact Time; VIF = Vertical Impact Force; HBF = Horizontal Braking Force; VPF = Vertical Propulsive Force; HPF = Horizontal Propulsive Force; HBFR = Horizontal Braking Force Ratio; ES = Effect Size; PEN = Penultimate foot contact ; FINAL: Final foot contact 
Table 5. Comparisons between penultimate and final foot contact mechanical variables and presentation of braking force ratio values

\begin{tabular}{|c|c|c|c|c|c|c|}
\hline & $\begin{array}{l}\text { PEN VIF } \\
(\text { N.kg-1) }\end{array}$ & $\begin{array}{l}\text { FINAL VIF } \\
(\text { N.kg-1) }\end{array}$ & $\mathrm{p}$ value & $\begin{array}{l}\text { PEN vs } \\
\text { FINAL ES }\end{array}$ & $\begin{array}{l}\text { ES magnitude } \\
\text { descriptor }\end{array}$ & $\begin{array}{l}\text { Statistical } \\
\text { power }\end{array}$ \\
\hline $\begin{array}{c}\text { Mod505 } \\
\text { left }\end{array}$ & $18.26 \pm 3.92$ & $16.16 \pm 5.00$ & 0.026 & 0.47 & Small & 0.998 \\
\hline \multirow[t]{2}{*}{$\begin{array}{c}\text { Mod } 505 \\
\text { right }\end{array}$} & $17.57 \pm 4.52$ & $16.91 \pm 3.78$ & 0.376 & 0.16 & Triv & 0.466 \\
\hline & $\begin{array}{l}\text { PEN HBF } \\
(\text { N.kg-1) }\end{array}$ & $\begin{array}{c}\text { FINAL HBF } \\
(\mathrm{N} . \mathrm{kg}-1)\end{array}$ & $\mathrm{p}$ value & $\begin{array}{c}\text { PEN vs } \\
\text { FINAL ES }\end{array}$ & $\begin{array}{c}\text { ES magnitude } \\
\text { descriptor }\end{array}$ & $\begin{array}{c}\text { Statistical } \\
\text { power }\end{array}$ \\
\hline $\begin{array}{c}\text { Mod505 } \\
\text { left }\end{array}$ & $12.49 \pm 2.70$ & $12.34 \pm 2.54$ & 0.788 & 006 & & 0.140 \\
\hline $\begin{array}{l}\text { Mod } 505 \\
\text { right }\end{array}$ & $12.11 \pm 2.82$ & $13.31 \pm 2.10$ & 0.025 & & Small & 0.998 \\
\hline
\end{tabular}

Key: VIF = Vertical Impact Force; HBF = Horizontal Braking Force; HBFR = Horizontal Braking Force Ratio; ES = Effect size PEN = Penultimate foot contact; FINAL: Final foot contact 


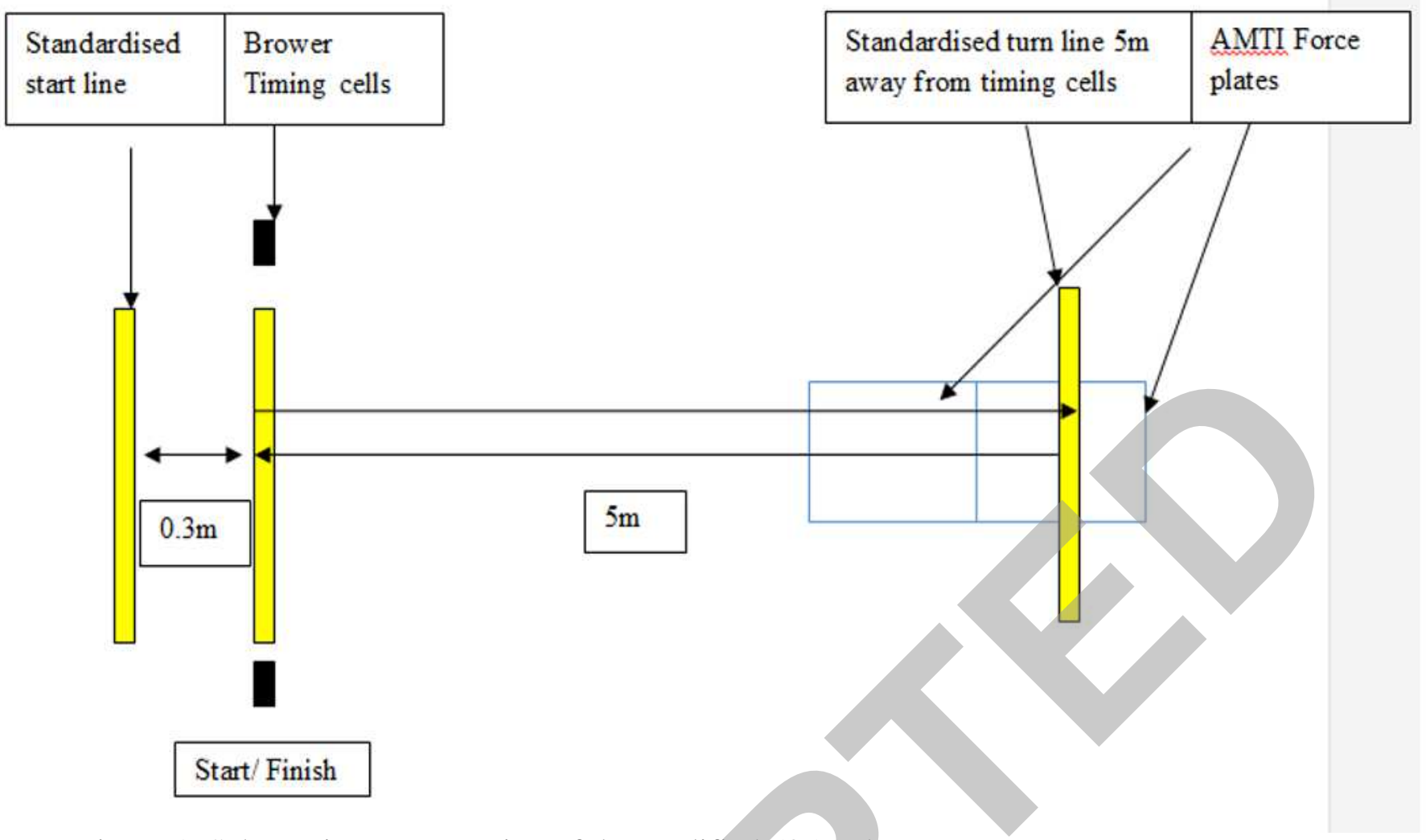

Figure 1. Schematic representation of the modified 505 task 